\title{
A UTILIZAÇÃO DE RECURSOS FORMAIS NA TRAGÉDIA FEDRA DE SÊNECA
}

\author{
JOSÉ EDUARDO DOS SANTOS LOHNER* \\ Faculdade de Filosofia, Letras e Ciências Humanas \\ da Universidade de São Paulo
}

\begin{abstract}
RESUMO: Tendo em vista que a peça Fedra de Sêneca apresenta em sua estrutura algumas particularidades em comparação com as outras peças supérstites, este estudo examina essa estrutura, o modo de ordenação dos elementos do enredo, chama a atenção para certos recursos formais observáveis no conjunto do poema bem como em algumas de suas seções, e procura mostrar a coerência dessas particularidades estruturais e recursos formais com o significado alegórico dado pelo autor ao enredo, na intenção de representar um tópico da doutrina estóica referente à manifestação das paixões na alma humana e a como os desequilibrios passionais e os males decorrentes deles se enquadrariam num mundo regido pela providência divina. Ressalta-se, assim, uma das características da poesia dramática de Sêneca, ou seja, a relevância do tratamento formal para o significado do poema.
\end{abstract}

PALAVRAS-CHAVE: poesia dramática latina; Sêneca; Fedra; estrutura formal.

O monólogo de Hipólito, na abertura da tragédia Fedra de Sêneca, tem um formato insólito em comparação com as falas que iniciam as outras peças desse autor. Isso pode ser verificado primeiramente, pela métrica empregada ali. Ao invés do prólogo habitual em versos trímetros iâmbicos falados, a peça tem início com um canto de Hipólito (v. 1-84) em dímetros anapésticos, do qual convém citar, como exemplo, os dois versos iniciais, com a indicação das sílabas em que recaem os ictus:

Ite, úmbrosás cingíte siluás

summáque montís iugá, Cecropii!!

Ide, rodeai as matas umbrosas

e o cume dos montes, filhos de Cécrope! 
O dímetro anapéstico é um metro tradicionalmente empregado nos cantos corais da tragédia. É um ritmo de caráter vivaz, próprio também das marchas militares e religiosas. A presença desse canticum, portanto, gera um efeito contrastante em relação ao tom sombrio freqüentemente encontrado na abertura de uma tragédia.

O mesmo se observa do ponto de vista do conteúdo : ao contrário do que costuma ocorrer em outras peças, não há, nesses versos iniciais, nenhuma referência clara ou direta aos eventos do enredo nem a fatos antecedentes a eles. Em lugar disso, o autor nos surpreende com uma cena dinâmica, tal como o ritmo - Hipólito coordenando a marcha dos caçadores em torno dos montes da Ática -, combinando elementos da poesia de caça (v. 35-52), gênero da poesia didática, e um hino à deusa Diana (v. 53-84). Em suma, o canto de Hipólito, a rigor, não se configura como um prólogo. Logo a seguir, a cena é transferida para o interior do palácio de Teseu, onde aparecem Fedra e a ama. É possível então constatar que o verdadeiro prólogo foi deslocado para a primeira fala de Fedra (v. 85-128). Nesses versos, trímetros iâmbicos, é que se encontram os elementos próprios da fala inicial de uma tragédia. Ali a personagem situa os conflitos tratados na peça, informa, num estilo alusivo e abreviado, sobre seu próprio caráter, sobre fatos anteriores que contextualizam e ao mesmo tempo prefiguram os acontecimentos da trama, como, por exemplo, se observa nos dois trechos que seguem:

\section{[...] stupra et illicitos toros}

Acheronte in imo quaerit Hippolyti pater.

Sed maior alius incubat maestae dolor.

Non me quies nocturna, non altus sopor

soluere curis : alitur et crescit malum

et ardet intus qualis Aetnaeo uapor

exundat antro [...] (v. 97-103)

[...] adultérios e leitos ilícitos

o pai de Hipólito busca no fundo Aqueronte.

Mas outra dor maior se abate sobre esta infeliz.

Nem o repouso da noite, nem o sono profundo

livraram-me dos tormentos: alimenta-se e cresce o mal

e ferve dentro, qual o fogo que se arroja

da cratera do Etna [...]; 
Fatale miserae matris agnosco malum:

peccare noster nouit in siluis amor.

Genetrix, tui me miseret : infando malo

correpta pecoris efferum saeui ducem

audax amasti [...] (v. 113-117)

Reconheço o mal fatal de minha pobre mãe:

Nosso amor aprendeu nas florestas a ser vicioso.

Mãe, tenho pena de ti: arrebatada por um mal infando,

o chefe bravio de um rebanho selvagem

amaste com ousadia [...].

Qual seria então a funcionalidade do canto de Hipólito dentro do poema? Numa primeira impressão, poder-se-ia dizer, citando Horácio (A.P., v. 19), que naquele momento inicial não havia lugar para tais coisas: caçadores, catálogo de regiões virgens, técnicas do manejo de cães, hino a Diana...

Em primeiro lugar, conforme foi dito há pouco, é correto admitir que, ao proceder assim, o autor gera na audiência um certo grau de estranhamento pelo contraste entre o que seria mais comum ocorrer - se não a própria fala de Fedra mencionada acima, pelo menos algo muito semelhante a isso - e o que de fato se dá, um vigoroso canto anapéstico trazendo imagens de conteúdo dinâmico e luminoso. Esse estranhamento pode ser melhor definido, nos termos da retórica, como um determinado grau de afeto, que irá interferir no modo de a audiência receber os eventos do enredo e de perceber a finalidade do poema. Ou seja, a ocorrência, na abertura da peça, de um canto que se pode dizer caracterizado pelo lirismo e pelo tom ameno, deve despertar na audiência o mesmo tipo de afeto suave, à diferença do que se dá, por exemplo, em peças como Medéia ou Tiestes, entre outras, onde já de início se estabelece um tom enérgico, patético e tenso. Isso, repetindo, exerce influência sobre a espectativa com relação aos eventos do enredo e ao modo de recebê-los. Lembrando novamente das palavras de Horácio, parece haver uma certa analogia entre esse procedimento de Sêneca e, mutatis mutandis, aquele preceituado na Arte Poética, v. 100-103:

[poemata] quocumque uolent, animum auditoris agunto.

Vt ridentibus adrident, ita flentibus adsunt

humani uultus; si uis me flere, dolendum est

primum ipsi tibi [...] 
[os poemas] para onde quiserem, conduzirão a alma do ouvinte.

Tal como os rostos humanos sorriem para os que riem, assim se juntam

aos que choram; se queres que eu chore, é preciso que sofras tu primeiro [...].

Ao que tudo indica, Sêneca não teria tido, nesta peça, a intenção de mover o medo, o horror ou a compaixão em sua platéia. Conforme os códigos da retórica antiga, o estabelecimento de um grau de afeto suave na audiência é o que melhor convém à finalidade de quem pretende passar um ensinamento ou demonstrar algo. Desse modo, pode-se dizer que, com o canto de Hipólito, o autor procurou, como que por meio de um sorriso, predispor os ouvintes ou mesmo leitores, especialmente os seus contemporâneos, para os quais tanto o enredo da fábula como os procedimentos da retórica eram familiares, a que, nesta peça, não tomassem em primeiro plano os conflitos e sofrimentos envolvendo os personagens, ou por outras palavras, a que não se fixassem em seu sentido imediato, e sim, dirigissem sua atenção para o que se estaria pretendendo ensinar por meio deles. Os elementos desse canticum apresentam, além do mais, um determinado grau de inverossimilhança que aponta também para para a possibilidade um tratamento alegórico dado ao enredo e aos personagens. Essas características, portanto, atuam como indicadores de que a peça não está centrada no patético, o que permite à audiência se posicionar numa perspectiva adequada.

Este parece ser um primeiro e importante aspecto. Outro passo no esclarecimento da questão formulada acima pode ser dado, ao se examinar a estrutura formal desta peça. Convém então começar com algumas observações sobre o primeiro coro (v. 274-356), que separa o primeiro e o segundo ato. Este canto coral apresentase na forma de um hino que, apesar de endereçado a Vênus, louva indiretamente o poder da deusa ao descrever a ação implacável de Cupido sobre todos os seres, mortais e imortais, e serve ao mesmo tempo como defesa para o estado afetivo de Fedra, revelado um pouco antes. Tendo em vista o aspecto estrutural, parece existir um certo paralelo entre este canto e aquele realizado por Hipólito na abertura da peça. Primeiramente há entre eles um ponto comum no que concerne ao gênero: ambos empregam a forma de um hino - apesar de ocupar só a última parte do poema, o hino a Diana não deixa, por isso mesmo, de ser uma forma proeminente no canto de Hipólito. Em segundo lugar, vendo de outro ângulo o paralelo entre esses poemas, verifica-se que há entre os dois cantos uma relação antitética. No momento, pode-se dizer que isso se dá pela simples razão de que cada um deles celebra uma força divina relacionada respectivamente aos dois personagens em cuja 
oposição estarão centrados os conflitos do drama. Junta-se a esses fatores ainda um outro, também relativo à estrutura, mas de natureza estritamente formal, e por conseguinte, perceptível apenas, por assim dizer, de um ponto de observação mais próximo. É possivel averiguar a existência de uma proporção simétrica entre os dois cantos: o número de versos que compõem os dois trechos em questão é quase exatamente o mesmo, ou seja, 84 versos para o canto de Hipólito e 82 versos para o canto coral. A relevância desse dado, visto como decorrente de um procedimento deliberado, poderá ser confirmada por sua coerência com o desenho sugerido pela organização formal do poema desta peça em seu conjunto. Além disso, essa quase idêntica proporção dos dois cantos espelha, de certo modo, o mesmo recurso utilizado, de forma mais patente, numa outra parte coral, conforme será mostrado depois. Por fim, será possível ainda constatar que esse expediente se mostra perfeitamente coerente e significativo em relação ao conteúdo do enredo, tal como é tratado por Sêneca.

Resumindo, é possível afirmar que aquela seção inicial da peça tem uma função retórica, enquanto fator que desperta na audiência um certo tipo de expectativa quanto ao significado e finalidade do poema, e uma função estrutural no desenho arquitetônico da peça, enquanto elemento simetricamente oposto ao canto do primeiro coro.

Delineadas algumas respostas para a questão levantada acerca da função do canto de Hipólito, é preciso então verificar melhor o sentido a que estaria remetendo a oposição estrutural estabelecida entre os dois cantos e, em seguida, a relação deste último fato com outras seções do poema.

A primeira questão está relacionada ao que se disse sobre esta não ser um tipo de tragédia centrada no caráter patético que o significado imediato dos eventos pode sugerir. Nesta tragédia, conforme já assinalado, Sêneca parece utilizar uma figura particularmente adequada à função didática, ou seja, a alegoria. O sentido alegórico atribuído aos personagens e eventos, fato sinalizado no poema desde o início, é explicitado pelo próprio texto. A extensa fala de Hipólito em louvor das primeiras gerações de homens (v. 483-564) perece ter a função de novamente orientar a audiência quanto ao modo de receber e interpretar os elementos da fábula. Essa identificação do jovem príncipe com os primeiros homens, num longo discurso aparentemente inoportuno, ganha sentido caso se veja, em tal fato, a intenção de associar a figura de Hipólito a esse perfil da alma humana ainda não submetida às paixões, de modo que a figura de Fedra contrapondo-se à dele, retratataria o estado oposto e subseqüente, o da alma subjugada pelos distúrbios passionais. 
O mito da Idade de Ouro, esse lugar-comum da literatura antiga, servia perfeitamente como imagem apta a ilustrar uma das idéias defendidas pela doutrina estóica sobre as paixões, ou seja, a de que o estado passional não é inato no homem, mas um modo de ser da própria razão, o qual, num determinado momento, deve necessariamente se impor em lugar do estado natural, isento dos desequilíbrios passionais, uma vez que a alma nesse estágio imaturo não possui virtudes, adquiridas somente por meio do exercício, num processo de educação (Bréhier, 1951, p. 157s. 235s). Tal concepção pode ser averiguada num comentário de Sêneca sobre este próprio mito, feito numa das Epistolas a Lucilio:

Ignorantia rerum innocentes erant: multum autem interest, utrum peccare aliquis nollit an nesciat. Deerat illis iustitia, deerat prudentia, deerat temperantia ac fortitudo. Omnibus his uirtutibus habebat similia quaedam rudis uita : uirtus non contigit animo nisi instituto et edocto et ad summum adsidua exercitatione perducto. Ad hoc quidem, sed sine hoc nascimur et in optimis quoque, antequam erudias, uirtutis materia, non uirtus est (Ep. 90, 46; cf. 94, 55s)

Eles eram inocentes por ignorância. Existe muita diferença entre não querer errar e não saber errar. Faltava-lhes a justiça, faltava a prudência, faltava a temperança e a força interior. Sua vida rude tinha certas qualidades similares a todas essas virtudes. A virtude não se instalou na alma, a não ser naquela que se instruiu e educou, e se conduziu, por um treinamento incessante, até o ponto mais elevado. Nascemos para isso, mas sem isso, e mesmo no que concerne aos melhores, antes que os instruam, existe a substância da virtude, não a virtude.

Este trecho, portanto, auxilia a compreensão da situação representada por Hipólito, em vista da conexão estabelecida, nesta peça, entre ele e a primeira geração de homens.

Definido o sentido alegórico do enredo, convém então reafirmar que nesta tragédia está colocada em primeiro plano a demonstração, por meio da figuração poética, de uma questão filosófica referente à manifestação das paixões na alma humana. $\mathrm{O}$ autor, em vista disso, assumindo o papel de quem ensina, não precisa nem deve persuadir pela emoção, mas pela razão, e pela via agradável, não pela via da dor. Isso pode certamente explicar o modus operandi observado nesta peça, as particularidades formais e estruturais nela encontradas, bem como a originalidade na disposição dos dados do enredo. 
Com relação a este último item, quando se compara a disposição dos elementos da fábula na peça de Sêneca e na de Eurípedes, conclui-se que a originalidade da versão latina se deve sem dúvida à necessidade de adequar esses elementos a um propósito original. Assim, na peça latina Hipólito morre antes de Fedra: sua fuga se dá no terceiro ato; o relato de sua morte é feito no ato seguinte. Na versão grega, Hipólito morre depois de Fedra, quase no final da peça. Além disso, ele não é destroçado e retorna vivo diante de Teseu. A seqüência cronológica adotada por Sêneca é, assim, coerente com a sucessão dos dois estados de alma figurados por esses personagens, bem como o destroçamento de Hipólito é bastante eloqüente enquanto figuração da perda do estado de inocência. Fedra é colocada por Sêneca em confronto direto com o jovem príncipe, revelando a ele seu amor (v. 589-718). Em Eurípedes, na mesma situação, aparece a ama em lugar de Fedra. O confronto direto certamente retrata melhor o conflito, dentro da alma, entre dois estados de consciência. Hipólito, além do mais, foge dizendo-se contaminado pelo contato com Fedra e não volta mais à cena, o que remete à perda irreparável do equilíbrio inato no homem, depois que se introduzem as paixões. Por fim, a própria entrada deste personagem na peça, antecedendo a de Fedra - ao que tudo indica, uma inovação de Sêneca (Grimal, 1963) -, parece atender à relação cronológica entre os estados de consciência que esses personagens estão representando.

Respondendo agora mais diretamente a questão sobre o significado daquele recurso formal envolvendo as duas partes cantadas, a de Hipólito dedicada à deusa Diana e a do primeiro canto coral, dedicada a Vênus, parece correto pensar que o autor buscou representar por meio do referido recurso o modo de relação entre os dois estados de consciência, na peça vinculados simbolicamente a essas divindades.

Abra-se aqui um breve parêntesis para assinalar o fato de que essas divindades, da mesma maneira que os personagens centrais, são tomadas como meras figurações poéticas relativas aos dois modos de ser da alma humana. $O$ próprio texto assinala isso numa passagem da fala da ama (v. 195-203) em que se faz referência às figuras de Vênus e Cupido:

Deum esse amorem turpis et uitio fauens

finxit libido, quoque liberior foret

titulum furori numinis falsi addidit.

Natum per omnis scilicet terras uagum

Erycina mittit, ille per caelum uolans

proterua tenera tela molitur manu 
regnumque tantum minimus e superis habet;

uana ista demens animus asciuit sibi

Venerisque numen finxit atque arcus dei

Que o amor é um deus, quem forjou tal idéia foi o desejo torpe

e que fomenta o vício; e para que tivesse maior liberdade,

deu à sua fúria nome de deus fictício.

[Vênus] Ericina como que envia por todos os lugares

seu filho errante; ele, voando pelo céu,

atira com suas tenras mãos setas atrevidas,

e tamanho reino possui o menor dos deuses;

essas imagens vãs uma alma insana elegeu para si

e inventou a deusa Vênus e o arco do deus.

Complementando o que se disse mais acima, a simetria formal entre os dois cantos parece querer indicar a idéia de que haja um mesmo tipo de proporcionalidade na interação daqueles dois modos de ser opostos da alma. Essa idéia adquire um significado mais claro em vista do que se pode extrair pela leitura do texto da terceira ode coral, v. 959-988, entre o terceiro e o quarto ato. Mais uma vez as observações de Horácio na Arte Poética podem ajudar a entender certas particularidades da poesia dramática de Sêneca. Nos versos citados a seguir (A.P. 361-362), Horácio, fazendo uma analogia entre a pintura e a poesia, ressalta a importância da perspectiva de quem observa a obra de arte:

Vt pictura poesis; erit quae, si propius stes,

te capiat magis, et quaedam, si longius abstes

Tal como a pintura é a poesia; haverá uma que, se estiveres mais perto, irá te agradar mais, e uma outra, se ficares mais longe.

A poesia de Sêneca, em virtude do uso dos recursos formais que nela com freqüência se observa - a tragédia Agamêmnon é uma outra peça em que se nota um procedimento de construção similar ao encontrado em Fedra -, parece enquadrarse melhor no tipo de poesia dramática que, conforme a comparação acima, adquire contornos mais nítidos ou "dá melhor foco" se observada de perto. Uma certa comprovação disso já é possível pelo que se apontou até aqui. Porém o texto da ode coral, transcrito a seguir, exemplifica melhor esse fato, além de dar referências que 
servem para a compreensão tanto do conteúdo quanto das particularidades formais da tragédia agora em questão.

O magna parens Natura deum,

960 tuque igniferi rector Olympi,

qui sparsa cito sidera mundo

cursusque uagos rapis astrorum,

celerique polos cardine uersas,

cur tanta tibi est cura, perennes

965 agitare uias aetheris alti,

ut nunc canae frigora brumae

nudent siluas; nunc arbustis

redeant umbrae; nunc aestiui

colla Leonis Cererem magno

970 feruore coquant uiresque suas

temperet annus? et cur idem,

qui tanta regis, sub quo uasti

pondera mundi librata suos

ducunt orbes, hominum nimium

975 securus abes; non sollicitus

prodesse bonis, nocuisse malis?

Res humanas ordine nullo

Fortuna regit, sparsitque manu

munera caeca, peiora fouens;

980 uincit sanctos dira libido.

Fraus sublimi regnat in aula.

Tradere turpi fasces populus

gaudet; eosdem colit atque odit,

tristis uirtus peruersa tulit

985 praemia recti. Castos sequitur

mala paupertas; uitioque potens

regnat adulter. $\mathrm{O}$ uane pudor,

falsumque decus!

Sed quid citato nuntius properat gradu,

990 rigatque maestis lugubrem uultum genis? 
Ó Natureza, magna genitora dos deuses,

960 e tu, regente do ignífero Olimpo,

que rápido os astros esparsos pelo mundo

e os cursos errantes das estrelas arrastas,

e giras os pólos sob célere eixo,

Por que tens tanto cuidado em as perenes

965 vias impelir do alto Éter,

para que ora o frio da alva bruma

desnude as florestas, ora aos arbustos

retornem as sombras, ora do Leão estival

as crinas façam cozer Ceres

970 sob intenso calor e suas forças

o ano tempere? E por que tu mesmo,

que reges algo tamanho, sob quem

os pesos do vasto mundo, equilibrados,

conduzem suas órbitas, dos homens descuidado

975 te ausentas, sem te importares

em dar amparo aos bons, ser nocivo aos maus?

As coisas humanas, sem qualquer ordem

a Fortuna rege, e espalha seus dons

com mão cega, favorecendo o pior.

980 Vence os virtuosos a cruel libido,

a fraude reina no palácio sublime.

Em conceder ao torpe o poder o povo

se alegra; cultua e odeia os mesmos homens.

A triste virtude leva prêmios perversos

985 de sua ação reta. Aos castos persegue

a maligna pobreza e, potente no vício,

reina o adúltero. Ó vão pudor

e enganoso decoro!

Mas por que o mensageiro avança com passo rápido

990 e banha o lúgubre rosto numa expressão aflita? 
Esta breve intervenção do coro vem logo após o clímax da peça, com a calúnia de Fedra contra Hipólito e a imprecação de Teseu. Seu conteúdo, se observado mais de longe, conforme a imagem de Horácio, parece não ter um vínculo direto com os eventos imediatos do enredo: o coro dirige uma queixa ao deus Júpiter pelo abandono em que parecem estar os homens e, em seguida, passa a censurar os males da vida humana. Mas ao submeter este poema a um olhar mais próximo, ou seja, a uma leitura mais atenta, torna-se aparente outra face de seu conteúdo, subjacente à organização formal, ficando clara, ao mesmo tempo, a relação de sua forma e significado com esses mesmos aspectos referentes a outras seções do texto deste drama.

O canto, em seu início, denota um conteúdo pautado pela doutrina estóica, com a invocação da Natureza - enquanto fonte de onde emana a existência de todas as coisas -, seguida pela de Júpiter - enquanto força que impulsiona o movimento do mundo -. Os elementos enumerados a partir daí aparecem como desdobramentos desses princípios, aliás indistintos para a física estóica, ${ }^{1}$ numa seqüência que reflete uma diferenciação de planos na organização do universo. Assim, por um lado, os versos 961-965 fazem menção aos eventos celestes, por outro, os versos 966 971, aos eventos da vida terrestre, sendo que os versos 974-988, descrevem eventos relativos à vida humana. Tal ordenação, considerando-se ainda o que é afirmado em cada uma das seções, certamente também alude à distinção, defendida por Platão e Aristóteles, entre o mundo supra-lunar, submetido a leis rigorosas, e o mundo sub-lunar, em que se situam as coisas humanas, entregue em parte ao acaso, apartado da lei divina, distinção, como se sabe, contrária aos fundamentos da doutrina estóica. ${ }^{2}$ Todavia, este poema também apresenta, agora do ponto de vista formal, uma outra articulação que, embora bem menos aparente, mostra-se mais significativa que aquela primeira. Pode-se constatar a ocorrência de uma divisão que distingue dentro do poema duas seções bastante simétricas, reunindo, na primeira delas, além das invocações mencionadas, a descrição do plano celeste e o da natureza terrestre (v. 959-972); e na segunda, a referência aos fatos da vida humana (v. 974988). Os limites desses dois segmentos ficam melhor delineados, bem como sua função passa a ter um significado mais claro ao se atentar para o conteúdo e para a composição da oração introduzida por sub quo (v. 972-974), que ocupa uma posição intermediária entre as duas seções. O conteúdo dessa oração refere-se ao movimento dos astros pelo céu, equilibrados sob a ação de Júpiter. Essa imagem é também representada por meio do arranjo dos elementos da frase, o que pode ser observado tanto na disposição original das palavras, dentro da métrica, quanto numa outra, mais esquemática, que ressalta os grupos sintáticos: 
sub quo uasti

pondera mundi librata suos

ducunt orbes;

sub quo

uasti pondera mundi librata suos ducunt orbes.

O mesmo desenho, sugerido pela distribuição simétrica dos componentes desta oração em torno de um elemento central, reflete-se também na estrutura formal de todo o poema. Isso se torna mais perceptível quando a oração acima é destacada no texto, ficando assim aparente uma divisão em duas seções com mesmo número de versos. A semelhança entre as duas estruturas, a da frase e a do poema, sugere uma relação analógica entre o sintagma nominal uasti pondera mundi e aquela primeira seção (v. 959-972), ficando o sintagma verbal suos ducunt orbes relacionado à segunda seção (v. 974-988). Obviamente os dois versos finais (989-990) não entram neste esquema formal, já que, sendo dois versos trímetros iâmbicos, e não dímetros anapésticos como os versos anteriores, são por isso falados pelo coro, não fazendo parte do canto coral. Para facilitar a observação do recurso formal empregado nesta ode, vem mais uma vez reproduzido o texto latino.

O magna parens Natura deum,

960 tuque igniferi rector Olympi, qui sparsa cito sidera mundo cursusque uagos rapis astrorum, celerique polos cardine uersas, cur tanta tibi est cura, perennes

965 agitare nias aetheris alti, ut nunc canae frigora brumae nudent siluas; nunc arbustis redeant umbrae; nunc aestiui colla Leonis Cererem magno

970 feruore coquant uiresque suas temperet annus? et cur idem, qui tanta regis, sub quo uasti 
pondera mundi librata suos

ducunt orbes, hominum nimium

975 securus abes; non sollicitus prodesse bonis, nocuisse malis?

Res humanas ordine nullo Fortuna regit, sparsitque manu munera caeca, peiora fouens;

980 uincit sanctos dira libido.

Fraus sublimi regnat in aula. Tradere turpi fasces populus gaudet; eosdem colit atque odit, tristis uirtus peruersa tulit

985 praemia recti. Castos sequitur mala paupertas; uitioque potens regnat adulter. O uane pudor, falsumque decus!

Vê-se então que essa imagem formal coloca em relação, por um lado, os eventos regulares e harmoniosos do mundo supra-lunar e, por outro, os eventos aparentemente caóticos da vida humana, como se fossem contrapesos em equilíbrio, pendendo sob um eixo que figuraria a razão divina, enquanto sustentáculo da ordem cósmica. Por meio desse artifício formal, obteve-se uma sobreposição de dois significados opostos. Em outras palavras, o conteúdo deste poema representa, com sua dupla face, a contraposicão de duas concepções da realidade - o que aliás também reflete uma antiga controvérsia entre o estoicismo e outras correntes filosóficas da época helenística, especialmente o epicurismo -, numa dessas concepções, o homem é mostrado como um ser isolado dentro do cosmos, apartado da divindade, entregue aos desequilíbrios ditados pelo acaso. Na outra, toda desordem da vida humana aparece ordenadamente integrada no conjunto dos eventos determinados e sustentados pela razão divina.

Nota-se ainda que, do ponto de vista retórico, em seu significado imediato este poema, conforme já foi dito, expressa uma queixa e faz uma censura aos desregramentos humanos. Porém, o significado velado em sua estrutura implica numa mudança da função do discurso, função que passa a ser ao mesmo tempo consolatória e, sobretudo, preceptística. 
Retomando agora aquela idéia, indicada mais atrás, sobre o significado da simetria formal entre o canto de Hipólito e o do primeiro coro, parece correto pensar que haja também uma relação analógica entre o desenho estrutural formado, de um lado, por tal simetria entre aqueles dois cantos e, de outro, por essa existente entre os dois segmentos da ode coral analisada acima. E essa relação analógica certamente se dá não só no nível formal, mas também no do conteúdo. De fato, as imagens da cena de caça, referidas no canto de Hipólito guardam uma relação com a imagem da movimentação dos astros referida naquela primeira seção da ode dirigida a Júpiter (v. 959-972), o que é confirmado inclusive por ecos no vocabulário. Assim, note-se primeiramente a imagem do vasto espaço virgem, em que se manifesta a força divina de Diana, e no qual se movimentam ordenadamente os caçadores, obedientes às instruções do chefe; e juntamente com isso, a trajetória circular e ascendente desse movimento em torno das florestas e do cimo dos montes, como vem indicado nestes versos:

Ite, umbrosas cingite siluas summaque montis iuga, Cecropii!

Celeri planta lustrate nagi quae saxosae loca Parnetho subiecta iacent, quae Thriasiis uallibus amnis rapida currens uerberat unda; scandite colles semper canos niue Riphaea (v. 1-8) Ide, rodeai as matas umbrosas e o cume dos montes, filhos de Cécrope! Errantes, com passos rápidos circulai a região que, sob o rochoso Parnete, se estende e a que o rio, correndo pelos vales de Tria, açoita com seu rápido fluxo; escalai as colinas sempre alvas como a neve dos Rifeus;

[...] Vos, qua tepidis

subditus austris, frigora mollit durus Acharneus, Alius rupem 
dulcis Hymeti; paruas alius

calcet Aphidnas (v. 20-24)

[...] Vós, por onde, exposto

aos tépidos austros, o duro monte

de Acarnas abranda a friagem. Um de vós

pise o rochedo do doce Himeto; outro

o solo da pequena Afidnas.

De outro lado, as imagens que retratam o furor e os distúrbios da ordem natural causados pela ação de Cupido, descritas no canto coral endereçado a Vênus, mostram, por sua vez, conexão com a seqüência de eventos referidos na segunda seção da ode a Júpiter (v. 974-988), desencadeados tanto pela ação da Fortuna - de caráter aleatório, tal como a ação de Cupido - quanto pelo domínio que exercem sobre os homens as paixões, em cuja origem está o desejo doentio (libido) ao qual o pequeno deus é identificado, conforme as palavras da ama citadas anteriormente (v.195-197).

Resta então considerar que o significado contido no desenho estrutural desta última ode, indicando a interação e o equilíbrio entre eventos de natureza oposta, todos igualmente subordinados à razão divina, transfere-se para os dois cantos iniciais, dada a semelhança do esquema formal, e por conseqüência, a mesma interação e complementaridade se reflete agora sobre a relação dos dois personagens vinculados a esses cantos, ou melhor dizendo, sobre a relação dos dois estados de consciência figurados por eles.

Verifica-se, em decorrência disso, que esta peça não tem um propósito moralizador num nível rasteiro, visando a glorificar o bem e rejeitar o mal, nem mostra uma visão pessimista sobre a vulnerabilidade da alma humana diante dos ataques das paixões. Esta obra, tal como ocorre com a ode coral a Júpiter, tem um propósito primeiramente preceptístico e virtualmente consolatório. Ela visa a passar um determinado ensinamento: demonstrar que as duas atitudes da alma, uma inconscientemente em comunhão com a ordem divina, outra conscientemente negadora dessa mesma ordem, manifestam-se com o mesmo grau de legitimidade dentro de um mundo coeso e regulado pela providência divina. ${ }^{3}$

É preciso ainda dizer que o esquema formal desta peça obviamente não se limita à relação apontada entre os dois cantos iniciais, o de Hipólito e o do primeiro coro, mas é completado pelas outras partes corais. Assim, é possível constatar que os dois últimos cantos do coro, aquele analisado há pouco, dirigido a Júpiter (v. 959- 
988) e o coro final (v. 1123-1153) que descreve a ação da Fortuna na vida humana, compõem outro setor do desenho estrutural desta tragédia. Os mesmos fatos observados naqueles dois primeiros cantos repetem-se nestes últimos: quanto à forma, assim como antes, os dois poemas apresentam uma extensão quase igual: 30 e 31 versos respectivamente; convém acrescentar, ao lado disso, que o tratamento dado à métrica dessas quatro partes cantadas mostra-se coerente com a natureza do conteúdo de cada uma. Ou seja, tanto o canto de Hipólito quanto a ode coral a Júpiter apresentam a mesma regularidade rítmica, determinada pelo uso de um único metro, o dímetro anapéstico. Em contrapartida, o canto coral endereçado a Vênus e sobretudo aquele último, sobre vicissitudes da vida humana, apresentam variação no esquema métrico, encontrando-se neles, além do ritmo anapéstico, alguns metros líricos como o sáfico menor, o asclepiadeu, o glicônio e o ferecrácio.

Considerando-se então o conteúdo, nota-se novamente a mesma relação antitética: a ode a Júpiter, como se viu, recria, em miniatura, a imagem do mundo, percebido numa escala cósmica, ressaltando sua ordenação rigorosa, tal como concebida pelos estóicos; já a última ode tem um enfoque mais restrito, ressaltando a irregularidade das situações humanas. Portanto, estes dois cantos refletem uma relação idêntica à daquelas duas seções da ode a Júpiter, tal como também se dá com os dois cantos iniciais, mais uma vez apontando para a mesma idéia de que realidades contraditórias tanto no âmbito interior da alma humana quanto no exterior coexistem em perfeito equilíbrio dentro de um mundo inteiramente perpassado pela razão divina.

A seguir, para conclusão deste estudo, e antes de uma breve sinopse de seu conteúdo, é preciso fazer duas observações: 1) em decorrência da ordenação das partes corais, o longo poema cantado pelo coro, celebrando a beleza de Hipólito (v. 736-834) fica numa posição central entre a outras partes cantadas, formando assim, junto com elas, um desenho também similar ao da estrutura do poema coral dos versos 959-988; 2) O personagem Teseu, na figuração alegórica da peça, parece remeter à situação de todo homem, aprisionado num estado passional, após a perda da condição representada pelo personagem Hipólito, perda causada por um impulso acionado pelo embuste de Fedra. A tentativa de recompor os destroços do filho, bem como a imagem do retorno das regiões infernais, empreendido por Teseu, podem ser interpretadas como uma menção aos esforços que deve empregar o homem na aquisição das virtudes, único remédio para os males da alma, conforme assinala trecho da Epistola a Lucílio, citado anteriormente.

Como o objetivo principal do autor, nesta tragédia, era transmitir um determinado ensinamento, foram utilizados por ele recursos de linguagem que se mos- 
tram em maior conformidade com a técnica didática. Desse fato parece resultar, em suma, o seguinte: 1) a função retórica do canto de Hipólito, conforme foi dito no início, orientando o modo de recepção dos elementos do enredo por parte da audiência; 2) o próprio uso da alegoria, que, dentre as figuras, é uma das que atendem melhor ao propósito didático, especialmente quando empregada como neste poema, ou seja, não de modo obscuro, mas claro, em função das indicações do próprio texto norteando a interpretação das imagens - a perspectiva alegórica, por si só, neutraliza o efeito patético dos eventos, dado o distanciamento e a não identificação que ela propicia, o que faz com que eles despertem não horror e comiseração, mas compreensão; 3) o caráter predominantemente lírico desta peça, devido à proeminência das partes cantadas, o que lhe confere um caráter suave, apropriado também a sua finalidade; 4) a forma rigorosamente esquemática de sua estrutura.

\section{Notas}

* Professor de Língua e Literatura Latina do Curso de Graduação da FFLCH-USP e Doutorando em Latim pelo Programa de Pós-Graduação em Letras Clássicas da FFLCH-USP.

1 Sêneca, Questões Naturais, II, 45: "Júpiter [...] a quem todo nome convém [...] Queres chamá-lo Natureza; não errarás. Ele é aquele de quem todas as coisas nasceram, por meio de cujo espírito vivemos".

2 Conforme comentário de Victor Goldschmidt (Goldschimidt, 1953, p. 84): "Recusando a distinção platônico-aristotélica entre o mundo sub-lunar e o mundo supralunar, e afirmando, por outro lado, uma estrita legalidade e uma providência sem fissuras, eles [os estóicos] haviam construído [...] um 'pressuposto metafísico' capaz de fundar e orientar uma explicação científica do mundo, levada até aos ínfimos detalhes: nada absolutamente, nem ser nem evento, podendo existir sem causa nem finalidade" (cf. p. 60).

3 Sobre esse tema, leia-se um trecho de Crisipo, filósofo do estoicismo antigo, citado e comentado por Plutarco: "Pois que a natureza universal se estende a tudo, tudo que acontece no universo e em qualquer uma de suas partes deverá acontecer conformemente a esta natureza e a sua razão, segundo uma série que não encontra obstáculo; pois que não há nada fora do universo para se opor a seu governo e em nenhuma de suas partes são possiveis um movimento ou um estado que não sejam conformes a esta natureza'. Que são, portanto, esses estados e esses movimentos das partes? Os estados são evidentemente os vícios e doenças da alma, avareza, amor do prazer, ambição, desregramento, injustiças; e os movimentos são os adultérios, os roubos, as traições, os parricídios. Crisipo é de opinião que nenhum dentre eles, grande ou pequeno, é contrário à razão de Zeus, à lei, à justiça, à providência, de tal 
maneira que a transgressão da lei não é contrária à lei, nem o ato injusto à justiça, nem a má ação à providência" (Plutarco, Contradições dos Estóicos, 34).

\section{REFERÊNCIAS BibLIOGRÁFICAS}

BRÉHIER, E. Chrysippe et l'Ancien Stoïcisme. Paris: P.U.F., 1951.

GOLDSCHIMIDT, V. Le Système Stoïcien et l'Idée de Temps. Paris: J. Vrin, 1953.

GRIMAL, P. L'originalité de Sénèque dans la tragédie de Phèdre. Revue des Études Latines. Paris, 1963.

HORÁCIO. Arte Poética. Tradução de R. M. Rosado Fernandes. Lisboa: Inquérito, 1984.

SÉNÈQUE. Lettres à Lucilius. Tradução de H. Noblot. Paris: Les Belles Lettres, 1971.

-. Tragédies. Tradução de L. Herrmann. Paris: Les Belles Lettres, 1971.

LOHNER, José Eduardo dos Santos. The use of formal poetic resourses in the Seneca's Phaedra.

ABSTRACT: Seen that Seneca's Phaedra exhibits in its structure some singularities by comparison to others remaining dramas, I examine that structure, the arrangement of plot's components, make known certains formal poetic resourses noticeable in the whole of poem, as well as in some of its sections and try to show the consistency of thouse structural singularities and formal resourses with the allegorical meaning ascribed by the author to the plot, with a view to represent a subject of stoical philosophy concerning the manifestation of passions in the human soul, and how passional troubles and evils that arises from them would fit in a world ruled by divine providence. So, I stand out characteristics of formal treatment of Seneca's drama and its importance for the meaning of poem.

KEY WORDS: latin dramatic poetry; Seneca; Phaedra; formal poetic structure. 